\title{
The single-macro domain protein LRP16 is an essential cofactor of androgen receptor
}

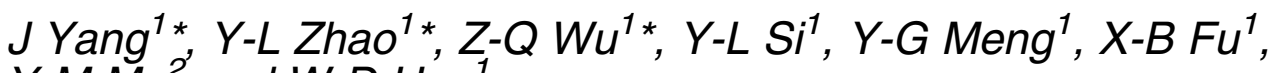 \\ $Y-M M u^{2}$ and $W-D H^{\prime}{ }^{1}$
}

\author{
${ }^{1}$ Department of Molecular Biology, Institute of Basic Medicine and ${ }^{2}$ Department of Endocrinology, Chinese PLA General Hospital, \\ Beijing 100853, P. R. China \\ (Correspondence should be addressed to W-D Han; Email: hanwdrsw69@yahoo.com) \\ *J Yang, Y-L Zhao and Z-Q Wu contributed equally to this work
}

\begin{abstract}
LRP16 is a special member of the macro domain superfamily, containing only a stand-alone macro domain functional module. Previous study demonstrated that the estrogenically regulated LRP16 cooperates with the estrogen receptor $\alpha$ and enhances the receptor's transcriptional activity in an estrogen-dependent manner. Here, we discovered that LRP16 binds to androgen receptor (AR) via its macro domain and amplifies the transactivation function of $A R$ in response to androgen. Similarly, we also discovered that LRP16 acts as a potential coactivator to amplify the transactivation of at least other four nuclear receptors (NRs). Importantly, we show that the single macro domain in LRP16 can serve as the AR coactivator. RNA interference knockdown of LRP16 leads to impaired $A R$ function and greatly attenuates the coactivation of $A R$ by other $A R$ coactivators such as ART-27 and steroid receptor coactivator-1. This interference also markedly inhibits the androgen-stimulated proliferation of androgen-sensitive LNCaP prostate cancer cells. However, LRP16 knockdown did not significantly affect the growth rate of AR-negative PC-3 prostate cancer cells. Furthermore, we observed the induction effect of LRP16 expression by androgen and established a feedforward mechanism that activated AR transactivation. Our results suggest that the macro domain protein LRP16 represents a novel type of cofactor of NR. They also indicate that LRP16 plays an essential role in AR transactivation.
\end{abstract}

Endocrine-Related Cancer (2009) 16 139-153

\section{Introduction}

The androgen receptor (AR) is a ligand-dependent transcription factor of the nuclear receptor (NR) superfamily. Like other NRs, AR is composed of a $\mathrm{N}$-terminal transactivation domain (NTD) harboring one or more hormone-independent activation function collectively named AF1, a highly conserved central DNA binding domain (DBD), and a C-terminal domain (CTD) that contains both the AR ligand-binding domain (LBD) and harbors a ligand-dependent activation function (AF2; Brinkmann et al. 1989). In the absence of androgen, AR is inactive and unable to influence the transcription rate of its target gene promoters. Androgen-bound AR engages with androgen response elements in the promoter and enhancer regions of target genes and regulates transcription (White \& Parker 1998).
AR-mediated transcription is a highly complex process involving multiple of coregulatory factors (McKenna et al. 1999, McKenna \& O’Malley 2002, Rosenfeld et al. 2006). The AR LBD is the major protein-protein interaction surface used to recruit coactivators (Chang \& McDonnell 2005). The last decade has seen the identification of an overwhelming number of AR coregulators, including ART-27 (Markus et al. 2002, Heemers \& Tindall 2007). Most coactivator proteins contain different activation domains or enzyme activity modules such as classical histone acetylase (HAT), bromo, chromo, SET (Su(var) 3-9, enhancerof-zeste, Trithorax) and ATPase domains, by which coactivators facilitate AR transactivation (Heemers \& Tindall 2007). The AR activity is not only critical for male sex determination but also plays an essential role for normal prostate development and malignant growth (Lee \& Chang 2003, Dehm \& Tindall 2006, 2007). 
The macro domain is an evolutionary conserved sequence (130-190 amino acids) that can be found in all organisms (Karras et al. 2005). This domain was initially described as the non-histone region of the variant histone macroH2A (Pehrson \& Fried 1992). In vertebrates, macro domains are sometimes found physically associated with proteins involved in ADPribosylation or poly(ADP-ribose) polymerization, as well as ATP-dependent chromatin remodeling (Aguiar et al. 2005, Goenka \& Boothby 2006). Recent biochemical and structural analyses have revealed that macro domains are robust ADP-ribose and poly(ADP-ribose) binding modules (Karras et al. 2005, Egloff et al. 2006). However, the macro domain of histone macroH2A does not bind poly (ADPribose), but does bind the monomeric SirT1 metabolite $O$-acetyl-ADP-ribose with high affinity through its macro domain (Kustatscher et al. 2005). Emerging evidence indicates that macro domains modulate transcription by two models that are mutually exclusive. First, macro domains repress transcription when the domains are positioned to a promoter (Ladurner 2003); for instance, the macro domain of histone macroH2A has been implicated in the direct silencing of transcription by interfering with NF- $\kappa \mathrm{B}$ binding to its cognate sequence (Angelov et al. 2003) and that of the BAL family proteins represses transcription when tethered to a promoter (Aguiar et al. 2005). Second, macro domains activate transcription by functioning as a coactivator of some specific transcription factors. For example, a triplicated macro domain embedded within CoaSt6 protein can serve as a cofactor significantly enhancing IL4-induced Stat6 transactivation (Goenka \& Boothby 2006).

LRP16 is a special member of macro domain superfamily, the structure of which is simple in contrast to other macro domain protein members, composed of only a stand-alone macro module at its C-terminal region (Han et al. 2002, Aguiar et al. 2005). Given the unicity of its structural module, LRP16 should become an ideal model gene for clarifying and extending the biological function of macro domains. In a previous report, we demonstrated the potential of the macro domain acting as a coactivator by providing evidence that LRP16 cooperates with estrogen receptor $\alpha(\mathrm{ER} \alpha)$ and amplifies the receptor's transactivation (Han et al. 2007).

The LRP16 gene was originally isolated from human lymphocyte cells and predominantly localizes in the nucleus (Han et al. 2001, 2002). Although the expression pattern of LRP16 is ubiquitous in multiple human tissues and tumor cells (Han et al. 2001, Imagama et al. 2007), the expression of LRP16 strongly depends on the estrogen actions in ER $\alpha$-positive breast cancer cell lines (Zhao et al. 2005, Han et al. 2007, 2008). Testosterone can also activate the responsiveness of the LRP16 gene promoter via AR mediation in COS-7 cells (Han et al. 2003), which suggests that LRP16 is an AR response target in AR-positive prostate cancer cells. The expression level of LRP16 was positively linked to the proliferation and invasion of the ER $\alpha$-positive breast cancer and endometrial cancer cell lines and to the progression of primary breast cancers (Han et al. 2003, 2007, Liao et al. 2006, Meng et al. 2007). Furthermore, we have demonstrated that the estrogenically regulated LRP16 can interact with $\mathrm{ER} \alpha$ and enhance the receptor's transcriptional activity in a ligand-dependent manner, thus establishing a positive feedback regulatory loop between LRP16 and $\mathrm{ER} \alpha$ signal transduction (Han et al. 2007). Recently, a RUNX1-LRP16 fusion has been identified in a patient with acute monocytic leukemia (Imagama et al. 2007), which also suggests the transcriptional regulatory role of LRP16 when it is engaged with a transcription factor.

To further identify the transcription factors that potentially interact with LRP16, we herein performed a yeast two-hybrid screen with the full-length human LRP16 bait and a MCF-7 cDNA library. The wellknown AR coactivator ART-27 was identified to physically interact with LRP16. We further provided evidence that LRP16 is able to interact with AR independently of ART-27 mediation. The molecular determinants of LRP16-AR interaction and the functional significance were further characterized. We first uncovered a direct link between the coregulation of AR and the single macro domain of LRP16. Finally, we investigated the induction effect of LRP16 expression by androgen and established the existence of a feedforward mechanism that activated AR transactivation.

\section{Materials and methods}

\section{Chemicals, cell lines and siRNA}

Testosterone (T), 17 $\beta$-estradiol (E2), dexamethasone, and fenofibrate were purchased from Sigma. Troglitazone was obtained from Sankyo Pharmaceuticals (Tokyo, Japan). Steroid-deprived serum was prepared as described previously (Han et al. 2008). MCF-7, COS-7, LNCaP, PC-3, DU145, HeLa, and 293T cells were originally obtained from the American Type Culture Collection (ATCC, Rockvile, MD, USA) and cultured according to the instructions. The duplexes of LRP16 specific siRNA 374, 668, and the 
control-siRNA were synthesized as in a previous report (Han et al. 2007).

\section{Plasmids}

The pcDNA3.1-LRP16 was described previously (Han et al. 2003). The luciferase reporter $\mathrm{pGL}_{3}-\mathrm{S}_{0}$ and pGL3-S 2 , driven by an LRP16 promoter region, were described previously (Zhao et al. 2005). The reporter $3 \times$ ERE-TATA-Luc was provided by Prof. Donald P McDonnell (Duke University Medical Center, Durham, NC, USA). The reporters MMTV-Luc and PPRE-TK-Luc were provided by Dr Masatoshi Nomura (Kyushu University, Fukuoka, Japan) and Dr Jianzhong Zhang (Peiking Medical University, Beijing, China) respectively. The plasmids Gal4-Luc and Gal4-VP16 were obtained from Dr Guangchun Chen (Kyushu University). The steroid receptor coactivator 1 (SRC-1) expression vector pSG5-SRC-1 was described previously (Chauchereau et al. 2000). The pcDNA3-Flag plasmid was provided by Jie Liu (Beijing Institute of Biotechnology, Beijing, China). The full-length cDNA of AR, estrogen receptor $\beta$ $(\mathrm{ER} \beta)$, glucocorticoid receptor (GR), and peroxisome proliferator-activated receptor $\alpha(\operatorname{PPAR} \alpha)$ and $\gamma$ (PPAR $\gamma$ ) were PCR-amplified from their expression plasmids as previously described (Han et al. 2003), then cloned into pcDNA3.1 by using appropriate sites. The GAL4-VP16 was PCR-amplified from pACT plasmid and inserted into pcDNA3.1 at $\mathrm{BamH}$ I and Kpn I sites.

The yeast expression plasmid pGBKT7-LRP16 (Gal4 BD:bait gene fusion) was generated by inserting the full-length LRP16 cDNA in-frame at EcoR I sites of pGBKT7. For generating the glutathione S-transferase (GST)-LRP16 fusion plasmid and its mutants GSTLRP16-N (1-160) and GST-LRP16-C (161-324), the corresponding fragments were PCR-amplified and inserted at the EcoR I/Hind III sites of pGEX-6p-1 (Amersham Biosciences). For generating AR deletion mutants Flag-AR-N1 (1-266), AR-N2 (1-557), AR-N3 (1-621), and AR-C (622-920), the corresponding fragments were PCR-amplified and inserted at the Xho I/Xba I sites of pcDNA3-Flag. The full-length coding region of human ART-27 was amplified from GAL4 AD:ART-27 (pGADT7-ART-27) and then cloned into pcDNA3.1 at BamH I/EcoR I sites.

\section{Generation of cDNA library and yeast two-hybrid screening}

Total RNA of MCF-7 cells was extracted by use of TRIzol reagent (Invitrogen). The MCF-7 cDNA library was generated by using the BD SMART kit from
Clontech according to the manufacturer's instructions. Yeast two-hybrid screening used to identify LRP16 interacting proteins involved the Matchmaker twohybrid system 3 kit from Clontech according to the manufacturer's instructions.

\section{Cell transfection and cell proliferation assays}

pcDNA3.1-LRP16 or empty vector was stably or transiently transfected into $\mathrm{LNCaP}$ cells by use of Superfect reagent (Qiagen) according to the manufacturer's instructions. For stable transfection, cells were selected with $0.8 \mu \mathrm{g} / \mathrm{ml} \mathrm{G} 418$ (Invitrogen) for 2 weeks after 48-h transfection. All of the LNCaP parental cells were killed by G418 within this period. The selected cells were maintained as stable LRP16-expressing cells in media supplemented with $0.4 \mu \mathrm{g} / \mathrm{ml} \mathrm{G} 418$.

For cell proliferation assay, cells were plated onto 24-well plates at $1 \times 10^{4}$ cells/well in culture medium supplemented with 1 or $5 \%$ fetal bovine serum (Hyclone, Logon, UT, USA) and the medium was changed every 2 days. Cell proliferation rate was quantified by the use of CellTiter 96 Aqueous One Solution Cell Proliferation Assay (Promega). Each experiment was performed in triplicate and repeated on three occasions.

\section{GST pull-down assay}

GST and GST fusion proteins were prepared as described previously (Han et al. 2007). $\left[{ }^{35}\right.$ S $]$ methionine-labeled proteins were produced by the use of Promega's TNT coupled in vitro transcription and translation (IVT) system, with the expression vectors for ER $\beta$, GR, PPAR $\alpha$, PPAR $\gamma$, ART-27, VP16, AR, and its derivatives in pcDNA3.1 or pcDNA3-Flag. An amount of $20 \mu \mathrm{l}$ of the IVT reactions was incubated with GST or GST-fusion proteins bound to glutathionesepharose beads. The binding reaction was performed for $1 \mathrm{~h}$ at room temperature, and the beads were washed four times and resuspended in $20 \mu \mathrm{l}$ of $2 \times$ SDS-PAGE loading buffer, boiled for $5 \mathrm{~min}$, and resolved on a SDS$12 \%$ PAGE gel followed by radiophotography.

\section{Immunoprecipitation (Co-IP) and immunoblotting}

Cells were cultured in $10-\mathrm{cm}$ dishes and transfected with expression vectors. Forty-eight hours after transfection, cells were harvested and lysed in $500 \mu \mathrm{l}$ lysis buffer (20 mM Tris ( $\mathrm{pH} 7.4), 50 \mathrm{mM} \mathrm{NaCl}, 1 \mathrm{mM}$ EDTA, 0.5\% NP-40, 0.5\% SDS, 0.5\% deoxycholate, and protease inhibitors). An amount of $500 \mu \mathrm{g}$ of lysate $(1 \mu \mathrm{g} / \mu \mathrm{l})$ was precleared with $50 \mu \mathrm{l}$ protein A-Sepharose beads (Upstate Biotechnology, Lake 
Placid, NY, USA) for $2 \mathrm{~h}$ at $4{ }^{\circ} \mathrm{C}$. An appropriate amount of rabbit anti-AR antibody (Abcam, Cambridge, UK), rabbit anti-LRP16 antibody, rabbit anti-Flag antibody (Sigma) or rabbit non-specific immunoglobulin $\mathrm{G}$ ( $\operatorname{IgG}$ ) (Clontech) was then added and incubated overnight at $4{ }^{\circ} \mathrm{C}$. An amount of $100 \mu \mathrm{l}$ of preblocked agarose beads was added to the antibody/lysate mixture for another $2 \mathrm{~h}$ at $4{ }^{\circ} \mathrm{C}$, and the beads were pelleted and washed thrice with lysis buffer. Bound proteins were eluted in SDS sample buffer, subjected to SDS-PAGE and analyzed by immunoblotting. The rabbit anti-LRP16 antibody was described previously (Han et al. 2007). Rabbit antiART-27 (Aviva Systems Biology, Beijing, China), mouse monoclonal anti-Flag (Sigma), mouse monoclonal anti-PSA, mouse monoclonal anti-Gal4, rabbit anti-ER $\beta$, rabbit anti-GR, rabbit anti- $\beta$-actin (Santa Cruz Biotechnology, Santa Cruz, CA, USA), rabbit anti-PPAR $\alpha$ and anti-RRAR $\gamma$ (Aviva Systems Biology) were used for immunoblotting analyses.

\section{Luciferase assays}

Cells that had reached a $50 \%$ confluency rate in $35 \mathrm{~mm}$ dishes were cotransfected using Superfect (Qiagen). An amount of $0.25 \mu \mathrm{g}$ reporter, $0.25 \mu \mathrm{g}$ AR or other NR expression vectors or GAL4-VP16, and $0.5 \mu \mathrm{g}$ ART-27 and/or LRP16 expression vector were used to cotransfect cells. pRL-SV40 was cotransfected $(1 \mathrm{ng} /$ per well) with reporters to normalize the transfection efficiency. The total DNA was adjusted to $2 \mu \mathrm{g}$ per well with pcDNA3.1 empty vector. Cell extracts were prepared $42 \mathrm{~h}$ after transfection, and the relative luciferase activities were measured as described previously (Han et al. 2007).

An amount of $1 \mu \mathrm{g}$ of siRNA duplexes, $0.5 \mu \mathrm{g}$ MMTV-Luc, $0.25 \mu \mathrm{g}$ AR, $0.5 \mu \mathrm{g}$ ART-27 or SRC-1 expression vector, and $1 \mathrm{ng}$ pRL-SV40 were cotransfected using Lipofectamine 2000 according to the manufacturer's recommendations (Invitrogen). The total amount of nucleotides was adjusted to $4 \mu \mathrm{g}$ per well with pcDNA3.1 empty vector. Then, $48 \mathrm{~h}$ later, cells were harvested and the relative luciferase activities were measured as described previously (Han et al. 2007).

\section{Northern blot and quantitative real-time PCR}

Total RNA was extracted by TRIzol reagent (Invitrogen) and underwent northern blot analysis as previously described (Han et al. 2007). The membranes were probed with a 550 bp fragment of LRP16, a 621 bp fragment of AR, 243 bp of PSA and a 515 bp of $\beta$-actin fragment labeled with $\left[\alpha-{ }^{32} \mathrm{P}\right] \mathrm{dCTP}$ by random priming. For quantitative real-time PCR (qPCR) experiment, cDNA was prepared using Superscript II RNase $\mathrm{H}^{-}$reverse transcriptase (Invitrogen) and 1 to $2 \mu \mathrm{g}$ total RNA. cDNA was subjected to qPCR using the SYBR Green PCR Reagents kit (Bio-Rad). PCR primers were as follows: PSA sense, 5'ACCCTCAGAAGGTGACCAAGT- $3^{\prime}$; $P S A$ antisense, $5^{\prime}$-TGAAGCACACCATTACAGACAA-3'. HPRT sense, $5^{\prime}$-TTGCTCGAGATGTGATGAAAGGA-3'; HPRT antisense, 5'-TTCCAGTTAAAGTTGAGAGATCA-3'. Reactions were run on a LightCycler (Roche). Experiments were performed in triplicate for each data point.

\section{Statistical analysis}

Experimental results were expressed as the mean \pm S.E.M. Statistical analysis was performed using Chess software. All data were evaluated for paired variables to compare two groups. $P<0.05$ was considered to be statistically significant.

\section{Results}

\section{LRP16 interacts with AR coactivator ART-27 and AR}

To identify new interactors of LRP16, we performed yeast two-hybrid screening from a human breast cancer MCF-7 cDNA library using LRP16 as bait. This screening yielded 9 validated cDNA clones corresponding to 12 different LRP16-associated proteins. Among them, two clones code for the $\alpha$-class prefoldin family protein ART-27. Sequence analysis of the two ART-27 clones revealed that both clones retained a full-length coding fragment of ART-27 (amino acids 1-157).

ART-27 was previously identified to directly interact with AR and act as its coactivator (Markus et al. 2002). In addition, ART-27 is involved in other steroid and thyroid hormone receptor-mediated transcriptional activation (Markus et al. 2002). Therefore, we assessed the interaction among LRP16, ART-27, and AR in pull-down assays with the in vitrotranslated, $\left[{ }^{35}\right.$ S $]$ methionine-labeled full-length ART27 alone, AR alone or their combination incubated with GST-LRP16 or GST alone. ART-27 and AR were pulled down by GST-LRP16 but not by GST (Fig. 1A). Both ART-27 and AR were simultaneously pulled down by GST-LRP16 (Fig. 1A). These results suggested the reciprocal interaction among LRP16, ART-27, and AR proteins in a cell-free system.

To identify which domain in AR is necessary for AR-LRP16 association, we used a series of 

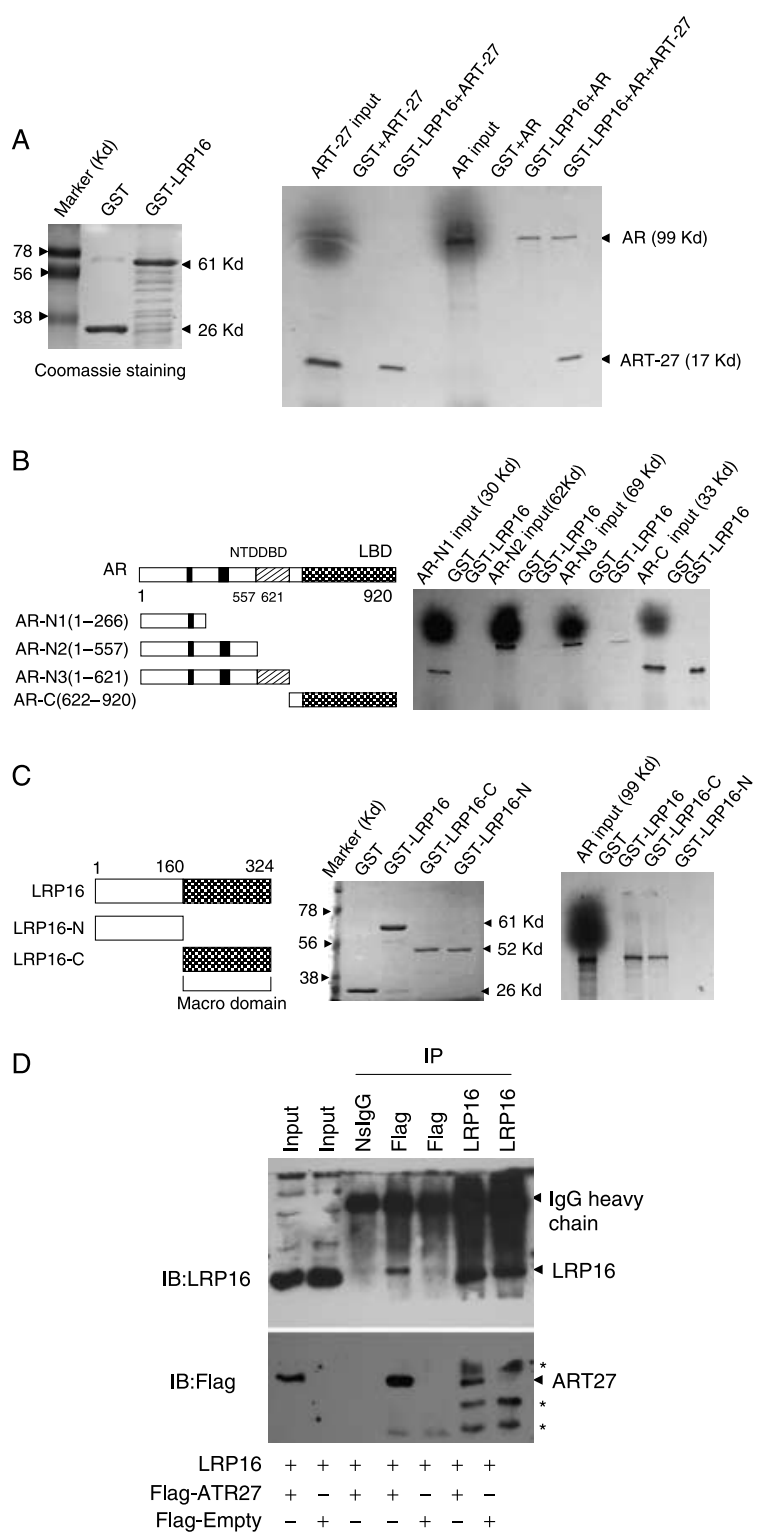

E
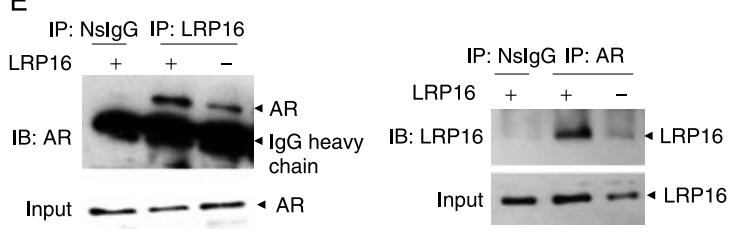

$\mathrm{F}$
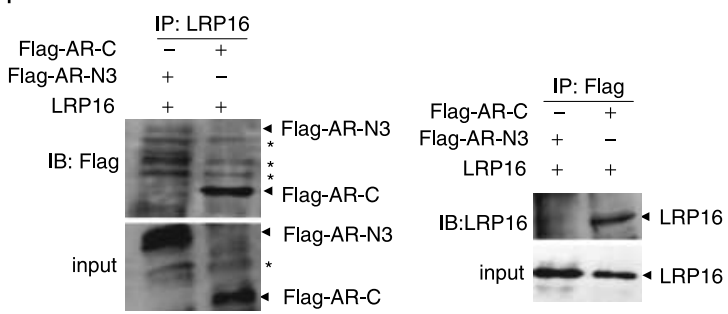

AR deletion mutants in GST pull-down assays. GST-LRP16 did not bind to AR-N1, intensively bound to AR-C, and weakly bound to AR-N3 and AR-N2 (Fig. 1B). As negative controls, the deletion mutants of AR did not associate with GST alone. Next, we tested the $\mathrm{N}$ - and $\mathrm{C}$-terminal deletion mutants of LRP16 for their ability to interact with AR. The fulllength AR was pulled down by GST-LRP16-C but not by GST-LRP16-N (Fig. 1C). Collectively, these results indicated that the interaction between AR and LRP16 is primarily mediated by the CTD of AR and the single macro domain of LRP16.

To confirm that LRP16 can interact with ART-27 or $\mathrm{AR}$ in cells, we performed Co-IP experiments. COS-7 cells were transiently cotransfected with LRP16 and Flag-ART-27 or LRP16 and flag empty vector. Cell lysates were precipitated with a flag antibody or LRP16 antibody, followed by immunoblotting analyses with their reciprocal antibody. An intense band corresponding to LRP16 was detected only in immunoprecipitate containing Flag-ATR-27 (Fig. 1D, upper panel). The presence of LRP16 in the ART-27-containing immune complexes is specific, because a non-specific antibody failed to immunoprecipitate LRP16. A reciprocal Co-IP experiment with LRP16 antibody revealed the presence of ART-27 in the immune complexes containing LRP16 as well (Fig. 1D, bottom panel). $\mathrm{LNCaP}$ is an AR-positive and androgen-sensitive

Figure 1 Interaction of LRP16 with ART-27 and AR in cell-free and cell systems. (A) Interaction of LRP16 with both ART-27 and AR on pull down assays. Coomassie blue-stained GST and GST-LRP16 are shown in the left panel. $\left[{ }^{35}\right.$ S]methioninelabeled ART-27 and AR were incubated with GST or GSTLRP16 as indicated in the right panel. Input reflects $10 \%$ of the protein incubated with the beads. (B) Mapping of AR domains that interact with LRP16 by GST pull-down assay. The left panel shows the schematic illustration of AR and its mutants. GST pull-down assays were performed with various $\left[{ }^{35} \mathrm{~S}\right]$-labeled $A R$ mutants and GST-LRP16 or GST alone (right panel).

(C) Mapping of LRP16 domains that interact with AR by GST pull-down assay. The left panel shows the schematic illustration of LRP16 and its mutants. The middle panel shows Coomassie blue-stained GST, GST-LRP16-N and GST-LRP16-C. GST pull-down assays were performed with $\left[{ }^{35} \mathrm{~S}\right]$-labeled $A R$ and GST-LRP16-N, GST-LRP16-C or GST alone (right panel). (D) Interaction of ART-27 and LRP16 in cells. COS-7 cells were transfected with the indicated plasmids. Forty-eight hours after transfection, cell lysates were immunoprecipitated and immunoblotted with the indicated antibodies. (E) Interaction of LRP16 with AR in LNCaP cells. Cells were transfected with or without LRP16. Forty-eight hours after transfection, whole cell lysates were immunoprecipitated and immunoblotted with the indicated antibodies. (F) Interaction of the CTD of AR with LRP16 in 393T cells. Cells were transfected with the indicated plasmids. Forty-eight hours after transfection, cells were lysed and underwent Co-IP experiments using the indicated antibodies. The asterisk reflects non-specific band. NslgG: non-specific IgG. 
prostate cancer cell line. The interaction between LRP16 and AR was determined by Co-IP experiments in LNCaP cells with or without LRP16 transfection in the absence of androgen treatment. Cell lysates were immunoprecipitated with a LRP16 antibody, and then underwent immunoblotting analysis with an anti-AR antibody. The endogenous AR was revealed in the immune complexes containing overexpressed or only endogenous LRP16 (Fig. 1E, left panel). Next, the same experiments performed in the reciprocal manner revealed both the exogenous and endogenous LRP16 detected in the AR antibody immunoprecipitated complex (Fig. 1E, right panel). To confirm whether the C-terminal region of AR is the primary region for AR-LRP16 association, we performed Co-IP assays using LRP16 and Flag-AR-N3 or LRP16 and FlagAR-C cotransfected 293T cells. Immunoblotting results showed that the AR-C and LRP16 were intensively and reciprocally coprecipitated (Fig. 1F). Although AR-N3 appeared to be coprecipitated in LRP16 antibody immunoprecipitated complex, its expression was very weak when compared with that of AR-C. Collectively, these results confirmed the interaction of LRP16 with ART-27 and AR in cells in an androgen-independent manner.

\section{Analysis of LRP16 interaction with other NR}

Given the high homology among NR family members, we presumed that LRP16 might be able to interact with other members of NR family proteins. To test this presumption, we performed GST pull-down assays using a panel of in vitro-translated, $\left[{ }^{35} \mathrm{~S}\right]$ methioninelabeled transcription factors and GST-fused LRP16 protein. The full-length ER $\beta$, GR, PPAR $\alpha$, and PPAR $\gamma$ but not VP16 could be pulled down by LRP16 (Fig. 2). Thus, these preliminary results suggested that LRP16 can interact not only with AR and ER $\alpha$ but also with at least four other NRs.

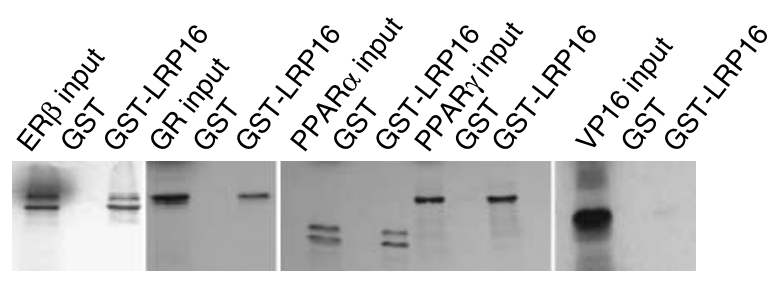

Figure 2 Interaction of LRP16 with other nuclear receptors in GST pull-down assays. GST pull-down assays were carried out with [ ${ }^{35}$ S]methionine-labeled ER $\beta$, GR, PPAR $\alpha$, PPAR $\gamma$, or VP16 in the presence of GST-LRP16. GST protein was used as a control. Input reflects $10 \%$ of the protein incubated with the beads.

\section{Overexpression of LRP16 enhances the transcriptional activation of its interacting NR}

To explore the possible functional significance of the interaction of LRP16 with ART-27 and AR, we examined the effect of LRP16 on AR-mediated transcription activity. AR-deficient HeLa cells were cotransfected with AR, AR-responsive reporter construct MMTV-Luc, LRP16, and/or ART-27. Cotransfection with LRP16 or ART-27 did not affect the AR-mediated transcription in the absence of testosterone stimulation (Fig. 3A). In the presence of testosterone $\left(10^{-7} \mathrm{M} / \mathrm{l}\right)$, AR up-regulated the reporter gene activity, which was further increased about threefold by either ART-27 or LRP16 cotransfection. Although ART-27 and LRP16 showed an enhanced effect on AR-mediated transcription, no additive or synergetic effect was observed on cotransfection of ART-27 and LRP16. Similar results were observed in AR-positive LNCaP human prostate cancer cells (Fig. 3B). These results indicate that LRP16 enhances AR-mediated transcriptional activation in a liganddependent manner.

The ability of LRP16 to affect transactivation by other NRs was also tested using transient transfection assays. Similar to the effect of LRP16 on AR transcriptional activation, LRP16 significantly enhanced reporter gene activities mediated by ER $\beta$, GR, PPAR $\alpha$, and PPAR $\gamma$ on stimulation with their corresponding ligands (Fig. 3C-F). Recall that VP16 did not interact with LRP16 in a cell-free system (Fig. 2A) and in mammalian two-hybrid hybridization (Han et al. 2007). We next tested the effect of LRP16 on VP16-dependent transcription. Consistent with this lack of interaction, LRP16 expression had no effect on GAL4-VP16 activity from a reporter plasmid containing five GAL4-binding sites upstream of the TK promoter (Fig. 3G). These results suggest that LRP16 might enhance the functional activity of its interacting NRs in a ligand-dependent manner.

\section{The macro domain of LRP16 enhances ligand-induced $A R$ transactivation}

Two of the most salient features of the LRP16 open reading frame (ORF) are its lack of modules represented in conventional transcriptional coregulators (e.g.,HAT, bromo, chromo, SET, or ATPase domains) and its membership in a small family of proteins containing macro domains. As a special member of the macro domain protein family, LRP16 exclusively contains a stand-alone macro domain, which mediates its interaction with $\mathrm{AR}$ as illustrated in Fig. 1C. A mutant of LRP16 consisting exclusively 
of a C-terminal region was compared with the fulllength LRP16. The macro domain of LRP16 increased AR-mediated reporter gene activity nearly as high as did the full-length LRP16 in transfection assays; however, the N-terminal region of LRP16 failed to enhance reporter gene activity relative to the background (Fig. 4A). To test whether the single macro domain of LRP16 can induce AR-mediated gene expression, we performed qPCR to measure the mRNA level of the well-known AR target gene PSA. Transduction experiments using endogenous AR-positive LNCaP cells confirmed that both the LRP16-C and the full-length LRP16 significantly amplified AR-mediated induction of PSA mRNA by testosterone $\left(10^{-8} \mathrm{M} / \mathrm{l}\right)$, when compared with the empty vector and the LRP16-N (Fig. 4B). As negative controls, neither the LRP16-C nor the full-length LRP16 changed the mRNA level of HPRT gene (Fig. 4B). Collectively, these findings demonstrate that the potentiation of ligand-induced AR transactivation by LRP16 relies on the presence of the macro domain.

\section{Knockdown of LRP16 sharply diminishes ligand-induced AR transactivation and hampers coactivation of the AR by ART-27 and SRC-1}

To further test whether LRP16 is required for AR transactivation, we used the MMTV-Luc reporter gene to evaluate the effect of LRP16 knockdown on AR activation status. Compared with the control siRNA, both LRP16-siRNA374 and LRP16-siRNA668 caused a specific reduction of LRP16 expression at both mRNA and protein levels in LNCaP cells but no change in expression of $A R$ and $\beta$-actin genes (Fig. 5A). Consistent with our previous report (Han et al. 2007), LRP16-siRNA374 was reproducibly better than LRP16-siRNA668 and therefore was used more frequently in later experiments. Luciferase assays revealed that the decrease of endogenous LRP16 markedly inhibited testosterone-induced AR transactivation (Fig. 5B). To determine whether knockdown of LRP16 affected the AR transactivation enhanced by ART-27 and other coactivators, we also cotransfected AR, MMTV-Luc, ART-27, or SRC-1 in LRP16inhibited LNCaP cells. The AR transcriptional response to ART-27 or SRC-1 was markedly attenuated by LRP16-siRNA374 relative to the control-siRNA and LRP16-siRNA668 (Fig. 5B). These results indicate that LRP16 is essential for ligand-induced AR transactivation and suggested that LRP16 is required for the potentiation of AR transactivation by some other coactivators.
To address the necessity for LRP16 in regulation of AR target genes, we used PSA to detect its expression in response to LRP16 knockdown. PSA expression at both mRNA and protein levels was significantly decreased by LRP16-siRNA374 and was partially decreased by LRP16-siRNA668 in LNCaP cells (Fig. 5A).

\section{Knockdown of LRP16 markedly inhibits the growth of androgen-sensitive LNCaP prostate cancer cells}

To determine the effect of the LRP16-AR association on the growth of androgen-dependent prostate cancer cells, we stably transfected LRP16 or empty vector into $\mathrm{LNCaP}$ cells for cell proliferation assays. However, ectopic LRP16 expression did not markedly promote cell growth when cells were cultured in normal or testosterone $\left(10^{-9} \mathrm{M} / \mathrm{l}\right)$-supplemented medium (data not shown). Next, we transiently transfected LRP16siRNA374 or control-siRNA into LNCaP cells for cell proliferation assays. Cells carrying LRP16-siRNA374 or control-siRNA showed no significant growth difference on culture in steroid-deprived medium (Fig. 6A). Testosterone $\left(10^{-12} \mathrm{M} / \mathrm{l}\right.$ and $\left.10^{-9} \mathrm{M} / \mathrm{l}\right)$ stimulated proliferation of $\mathrm{LNCaP}$ cells carrying either control siRNA or LRP16-siRNA 374, but the degree of testosterone-stimulated proliferation of LRP16siRNA374 expressing cells was much less than that of control-siRNA expressing cells (Fig. 6B and C). To determine whether LRP16 is required for cell growth independent of its effect on AR activity, we transiently transfected LRP16-siRNA374 or control-siRNA into AR-deficient PC-3 prostate cancer cells and performed cell proliferation assays. As shown in Fig. 6D, knockdown of the endogenous LRP16 did not significantly inhibited growth of PC-3 cells. Immunoblotting analysis revealed that the endogenous LRP16 in LNCaP and PC-3 cells was still partially inhibited by LRP16-siRNA374 at days 9 and 6 respectively after transfection (Fig. 6E). These findings suggest that inhibition of LRP16 expression blocks the proliferation of androgen-dependent prostate cancer cells through suppressing AR functional activity.

\section{Androgen stimulates LRP16 promoter response and upregulates LRP16 expression in AR-positive prostate cancer cells}

Previously, we demonstrated that the synthesis of LRP16 depends on estrogen activities in breast cancer cells, and in turn, LRP16 enhances ER $\alpha$ functional activity by cooperating with ER $\alpha$ (Han et al. 2007). We also previously observed that androgen can upregulate 

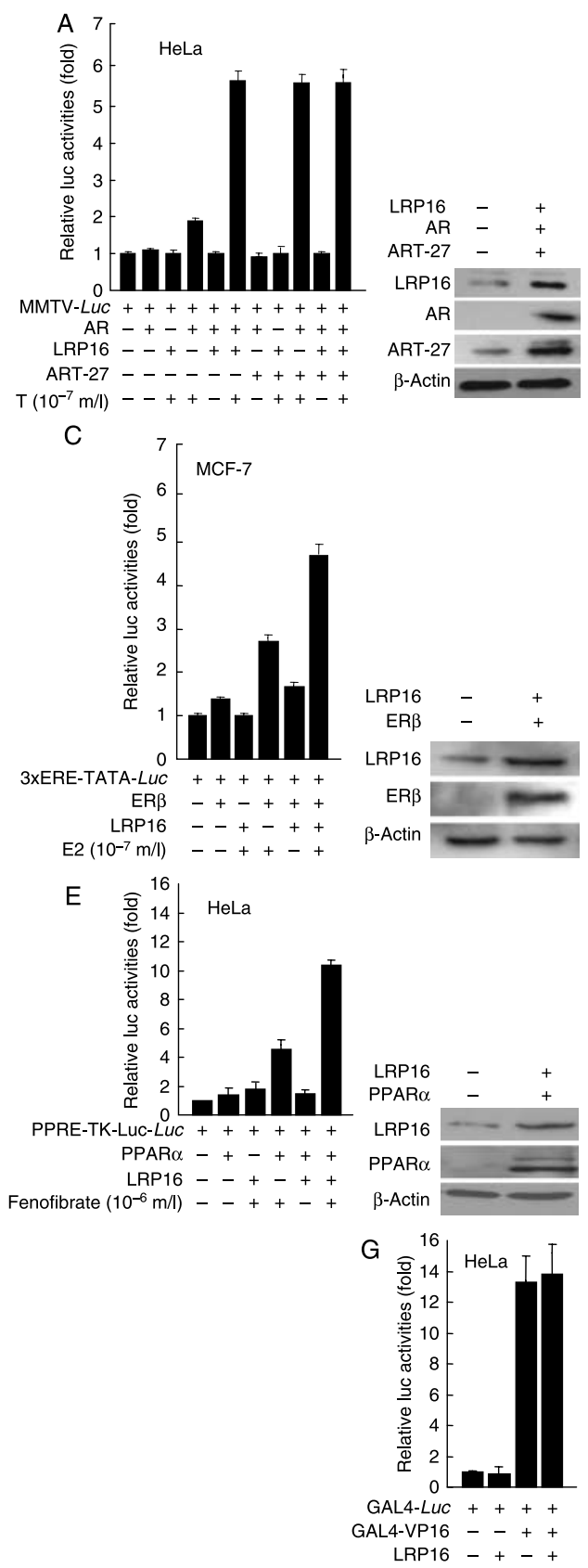

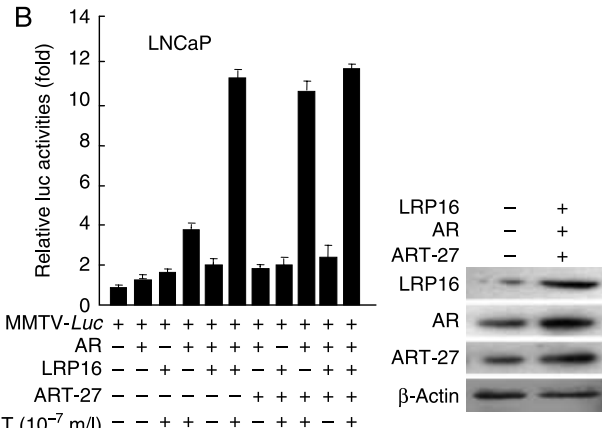

$\mathrm{T}\left(10^{-7} \mathrm{~m} / \mathrm{l}\right)--++-+++++$

D

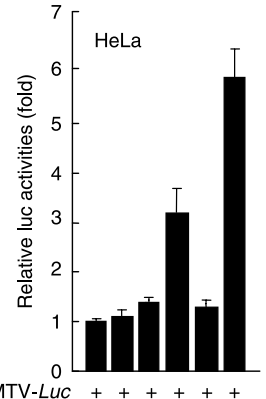

MMTV-LUC ++++++

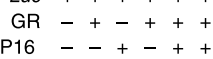

$\operatorname{Dex}\left(10^{-6} \mathrm{~m} / \mathrm{l}\right)--++-+$

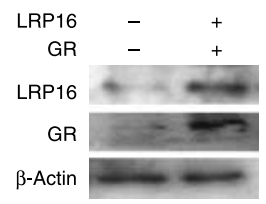

$\mathrm{F}$

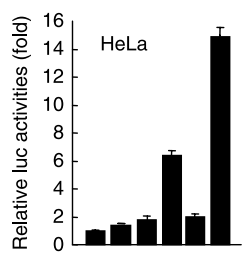

PPRE-TK-LUC-LUC ++++++

PPAR -+-+++

LRP16 - + + + +

$\operatorname{TGZ}\left(10^{-6} \mathrm{~m} / \mathrm{l}\right)--++-+$

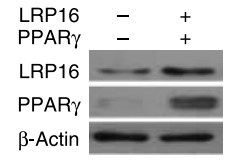

Figure 3 LRP16 enhances the transactivation of its interacting nuclear receptors in a ligand-dependent manner. (A) HeLa cells were transiently transfected with the indicated plasmids. Thirty hours after transfection, cells were stimulated with or without $10^{-7} \mathrm{M} / \mathrm{I}$ testosterone for $12 \mathrm{~h}$ before undergoing luciferase assay (left panel). Cell lysates were immunoblotted with the indicated antibodies to show the protein levels of the transfected genes (right panel). (B) LNCaP cells were transiently transfected with the indicated plasmids and were assayed as in A (left panel). Cell lysates were immunoblotted with the indicated antibodies to show the protein levels of the transfected genes (right panel). (C-G) The indicated plasmids were transfected into the indicated cells. Thirty-six hour after transfection, cells were treated with or without the indicated agonist for an additional $12 \mathrm{~h}$ and underwent luciferase assay (left panel). Cell lysates were immunoblotted with the indicated antibodies to show the protein levels of the transfected genes (right panel). Relative luciferase activity levels were normalized in all cases by luciferase reporter, pRL-SV40 and mock effector cotransfection and arbitrarily assigned a value of 1 . All experiments were performed in triplicate and were repeated at least thrice; the results are expressed as mean \pm S.E.M. 
LRP16 promoter activity via AR mediation in COS-7 cells (Han et al. 2003). On the basis of these findings and the fact that LRP16 serves as a coactivator of AR, we hypothesized the existence of a feedback loop between AR function and LRP16 expression. To evaluate this hypothesis, we first examined the androgen responsiveness of LRP16 promoter-driven reporter genes pGL-3 $\mathrm{S}_{0}$ and pGL3- $\mathrm{S}_{2}$ in $\mathrm{LNCaP}$ cells. Treatment with $10^{-10} \mathrm{M} / \mathrm{l}$ testosterone resulted in a 1.2- to 1.3-fold higher pGL3-S $\mathrm{S}_{0}$ and pGL3-S $\mathrm{S}_{2}$ reporter gene activities than without testosterone stimulation (Fig. 7A). The testosterone induction of the reporter activity of $\mathrm{pGL} 3-\mathrm{S}_{0}$ and $\mathrm{pGL} 3-\mathrm{S}_{2}$ was further enhanced (five- to sixfold) by their cotransfection with AR. These findings indicated that LRP16 is an androgen-responsive target gene in AR-positive prostate cancer cells. Next, we examined the induction effect of androgen on LRP16 expression at the protein level in $\mathrm{LNCaP}$ cells. LNCaP cells were treated with various concentrations of testosterone $\left(10^{-12}-10^{-6} \mathrm{M} / \mathrm{l}\right)$ for $24 \mathrm{~h}$, and then underwent western blot analyses. Testosterone, from $10^{-10}$ to $10^{-6} \mathrm{M} / \mathrm{l}$, significantly increased LRP16 expression, with the low concentration $\left(10^{-10} \mathrm{M} / \mathrm{l}\right)$ producing maximal induction (Fig. 7B). We further investigated the effect of $10^{-10} \mathrm{M} / \mathrm{l}$ testosterone on the expression level of LRP16 over $48 \mathrm{~h}$ (Fig. 7B). A significant increase of LRP16 expression was observed as early as $3 \mathrm{~h}$ after the addition of testosterone, which indicates that LRP16 is a testosterone-induced early response gene. The testosterone induction of LRP16 expression reached to the peak at $6 \mathrm{~h}$ and remained for at least $48 \mathrm{~h}$. To further confirm the regulatory effect of AR on LRP16 expression, we measured the expression of LRP16 protein in AR-positive and AR-negative human prostate cancer cell lines. LRP16 protein level was much lower in AR-negative PC-3 and DU145 cells than in AR-positive LNCaP cells (Fig. 7C). Finally, we overexpressed AR in PC-3 cells and observed a marked increase of LRP16 protein level (Fig. 7D). The induction of LRP16 in AR-overexpressed PC-3 cells indicated that the culture medium containing nonstripped serum provided the source of ligand for AR. Altogether, these data confirmed the induction effect of LRP16 expression by androgen via AR mediation and established a feedforward mechanism that activated the $\mathrm{AR}$ in human prostate cancer cells.

\section{Discussion}

The transactivation potential of an NR depends on the cofactors it recruits, a key mechanism by which NRs regulate transcriptional programs (McKenna et al.
1999, McKenna \& O’Malley 2002, Heemers \& Tindall 2007). A central finding of the present study is that the protein LRP16 serves as a coactivator that amplifies the transactivation function of AR in response to androgen. Similarly, LRP16 was suggested to amplify the transactivation of other NRs, including ER $\beta$, GR, $\operatorname{PPAR} \alpha$, and PPAR $\gamma$, in the presence of their corresponding agonists, by functioning as a potential coactivator. Importantly, we have uncovered a direct link between the coregulation of AR and the macro domain of LRP16. Knockdown of the endogenous LRP16 in cells significantly inhibited androgeninduced AR transactivation and diminished the coactivation of AR by other AR coactivators such as ART-27 and SRC-1. These findings suggest that the single macro domain protein LRP16 represents a novel type of cofactor of NRs and underscore a critical role of the macro domain in transcription modulation of multiple NRs.

Protein ADP-ribosylation modification is emerging as a regulatory process of protein function in prokaryotes and eukaryotes and may act on the level of signaling transduction, modulation of chromatin structure and epigenetic histone code (Hassa et al. 2006). The increased negative charge of ADPribosylated proteins may alter their spatial conformation and biological properties (Corda \& Girolamo 2003, Hassa et al. 2006). Previously identified as displaying an Appr-1"-p (ADP-ribose- $1^{\prime \prime}$-monophosphate) processing activity and robust ADP-ribose binding activity (Culver et al. 1994, Karras et al. 2005, Kumaran et al. 2005, Egloff et al. 2006), the macro domain may play roles in distinct ADP-ribose pathways, such as the ADP-ribosylation of proteins, an important post-translational modification (Kraus \& Lis 2003, Amé et al. 2004). In this study, we validated that a single macro domain within LRP16 is able to act as a coactivator of AR. Considering the biochemical characterization of macro domains binding to ADPribose, we proposed that LRP16 may act as a donor protein of ADP-ribose for ADP-ribosylation modification of NRs. Although the capacity of macro domains to transfer poly(ADP-ribose) to its partners is not yet authenticated, this hypothesis appears to be reasonable in that the poly(ADP-ribose) was indeed found to be transferred from its binding protein to another partner protein. For example, tankyrase, a member of PARP superfamily proteins, was found to confer poly(ADP-ribose) to its interacting protein TRF1, then ADP-ribosylation of TRF1 diminished its ability to bind to telomeric DNA (Smith et al. 1998). In general, because of the well-known function of the macro domain and the dependence of AR 

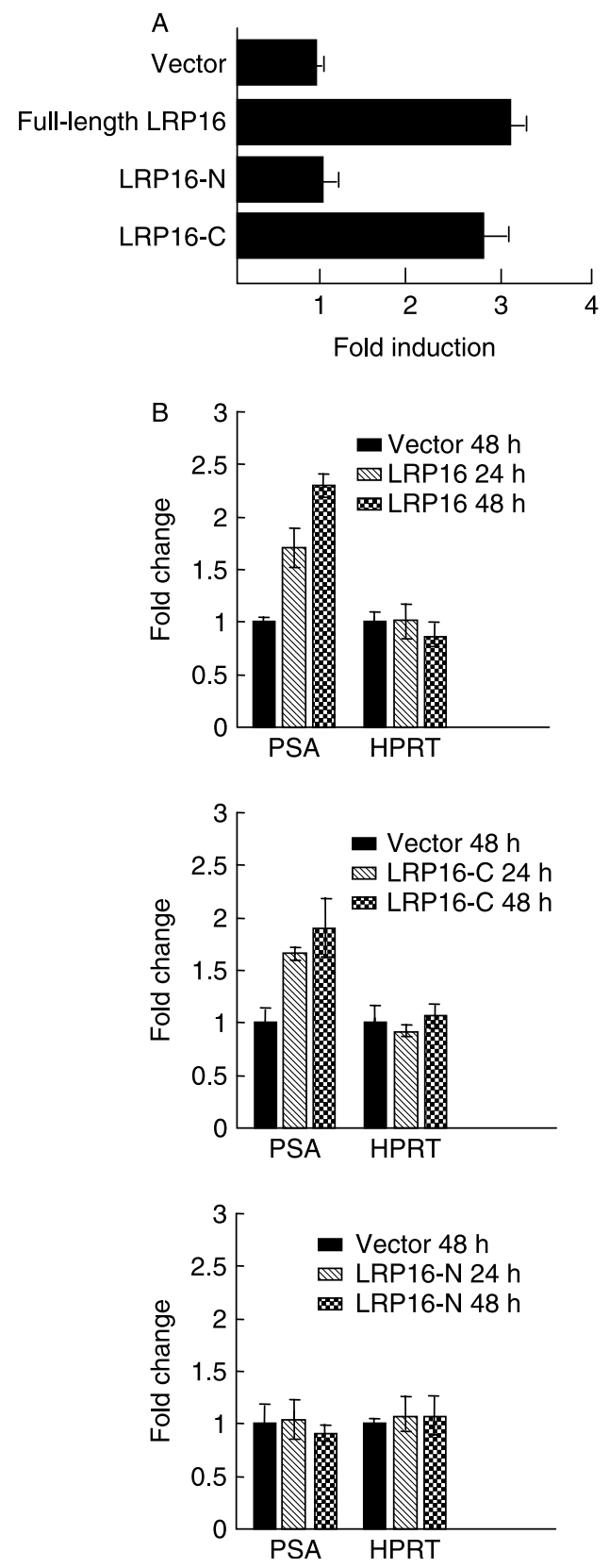

Figure 4 The macro domain of LRP16 enhances AR-mediated transcription. (A) Segments of LRP16 were transfected into LNCaP cells along with an AR-dependent MMTV-Luc reporter and $A R$. Thirty hour after transfection, cells were stimulated with $10^{-10} \mathrm{M} / \mathrm{I}$ testosterone for $12 \mathrm{~h}$ before luciferase assay. The relative normalized luciferase activity level for empty vector transfection was arbitrarily assigned a value of 1 . Shown are mean \pm S.E.M. from at least three independent experiments. (B) LNCaP cells were transfected with the indicated segments of LRP16 or empty vector. Twelve or $32 \mathrm{~h}$ after transfection, cells were stimulated with $10^{-10} \mathrm{M} / \mathrm{l}$ testosterone for an additional $12 \mathrm{~h}$. Endogenous mRNA expression of $P S A$ and HPRT were measured by qPCR. Data represent mean \pm s.E.M. from independent three experiments.
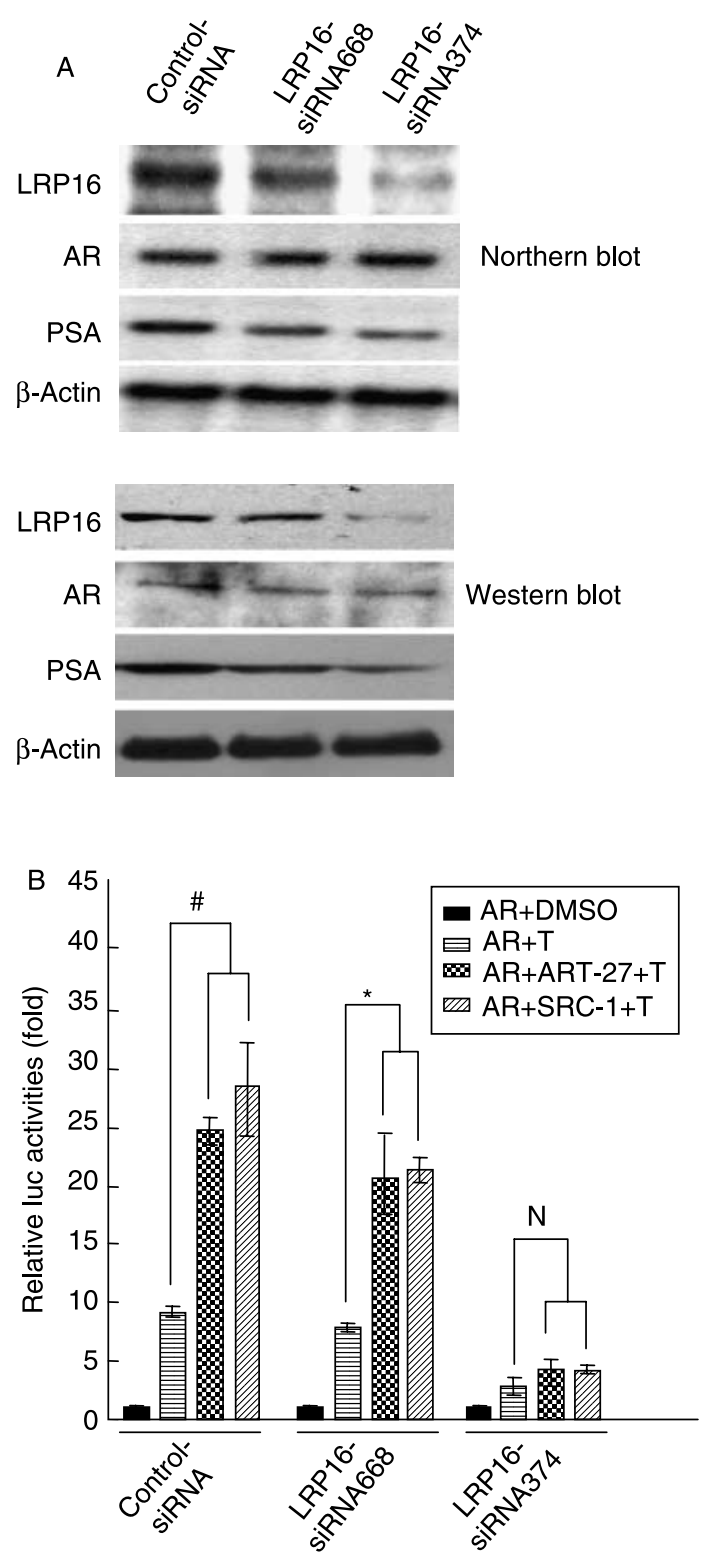

Figure 5 Knockdown of LRP16 sharply diminishes AR-mediated transcription. (A) LNCaP cells were transfected with the indicated siRNA. Forty-eight hour after transfection, the endogenous expression of LRP16, AR, PSA, and $\beta$-actin was monitored by northern blot and western blot analysis. (B) The indicated siRNA oligonucleotides were cotransfected with MMTV-Luc and the indicated plasmids into LNCaP cells. Thirty-six hour after transfection, cells were treated with $10^{-10} \mathrm{M} / \mathrm{l}$ testosterone or dimethyl sulfoxide (DMSO) for $12 \mathrm{~h}$ before luciferase assay. The relative luciferase activity levels were normalized by the use of mock effector transfection and arbitrarily assigned a value of 1 . All experiments were performed in triplicate and were repeated at least thrice; the results are expressed as mean \pm S.E.M. $(\# P<0.01$; ${ }^{*} P<0.05$; N $P>0.05$ ). 
transactivation on LRP16 as we show, we propose that the ADP-ribose binding/processing activity may be required for NR activation and might depend on interaction with LRP16.

Several areas of high sequence conservation are observed in macro domains. Structure analysis also revealed a conserved ADP-ribose binding pocket in
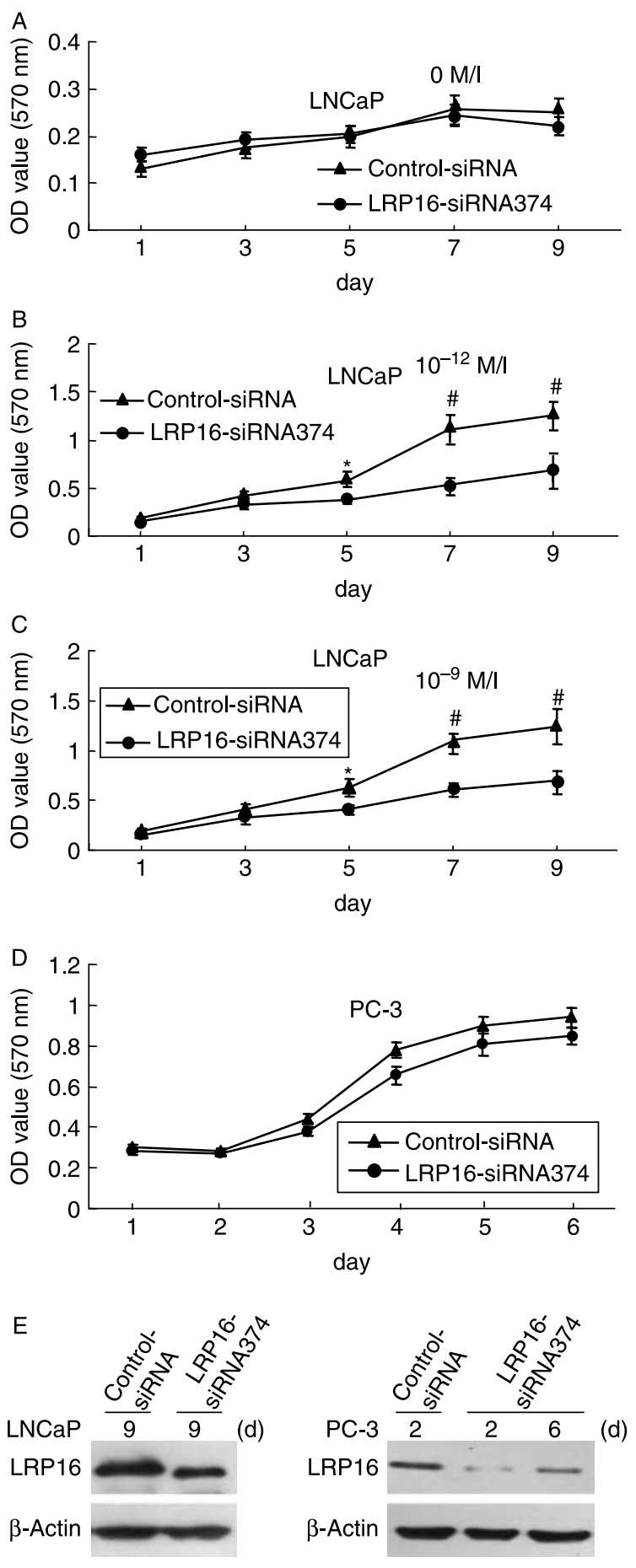

different macro domains (Karras et al. 2005, Egloff et al. 2006). However, only about $30-40 \%$ sequence homology is shared between any two macro domains (Aguiar et al. 2005, Egloff et al. 2006). A significant degree of sequence variation exists among different macro domains. These variations should be the determinants of predisposing the selectivity of macro domain binding partners. Through binding to different transcription factors, different macro domains are disposed to affect different cellular signaling transduction and transcription regulation. CoaSt6 was previously identified to cooperate with Stat6 but not Stat1 and amplify IL4-induced transactivation (Goenka \& Boothby 2006). In this study, several NRs were affected by LRP16. Further identification of LRP16interacting transcription factors will help clarify the partner selectivity of a single macro domain in LRP16 and the importance of the macro domain in transcription regulation.

GST pull-down and CoIP assay has shown to primarily interact with the AR CTD and probably the DBD and AF1b regions. By contrast, LRP16 was previously shown to primarily interact with the $\mathrm{ER} \alpha \mathrm{N}$ terminus by the two mammalian two-hybrid assays (Han et al. 2007). On the basis of the homologous sequence derived from the AR C terminus and $\mathrm{ER} \alpha \mathrm{N}$ terminus, we analyzed homology of NR along with the other receptors affected by LRP16; however, this search failed to reveal a definite LRP16 interaction motif. One plausible explanation is that LRP16 may associate with NRs through multiple interactions with different affinity. In addition, the AR differs from other

Figure 6 Knockdown of LRP16 blunts the androgen-responsive proliferation ability of $\mathrm{LNCaP}$ cells but does not inhibit proliferation of PC-3 cells. (A-C) LNCaP cells were cultured in medium supplemented with steroid-stripped FBS (5\%) for 3 days and then transiently transfected with LRP16-siRNA374 or control-siRNA. Forty-eight hour after transfection, cells were treated with testosterone at different concentrations for the indicated times. Cell proliferation rate was quantified by CellTiter 96 AQueous assay. Each data point represents the mean \pm S.E.M. of at least three independent experiments. $\left({ }^{\star} P<0.05, \# P<0.01\right)$. (D) PC-3 cells were transfected with either LRP16-siRNA374 or control-siRNA. Forty-eight hour after transfection, cells were plated onto 24 -well plates at $1 \times 10^{4}$ cells/well in the culture medium supplemented with $5 \%$ FBS. Cell proliferation rate was quantified by CellTiter 96 AQueous assay. Each data point represents the mean \pm S.E.M. of at least three independent experiments. (E) LNCaP cells transfected with the indicated siRNAs were treated as in C. $9 \mathrm{~d}$ after siRNA transfection, cells were cultured as in $C$ and the endogenous expression of LRP16 and $\beta$-actin was monitored by immunoblotting (left panel). PC-3 cells transfected with the indicated siRNAs were treated as in D. $2 \mathrm{~d}$ and $6 \mathrm{~d}$ after transfection, the endogenous expression of LRP16 and $\beta$-actin was monitored by immunoblotting (right panel). 

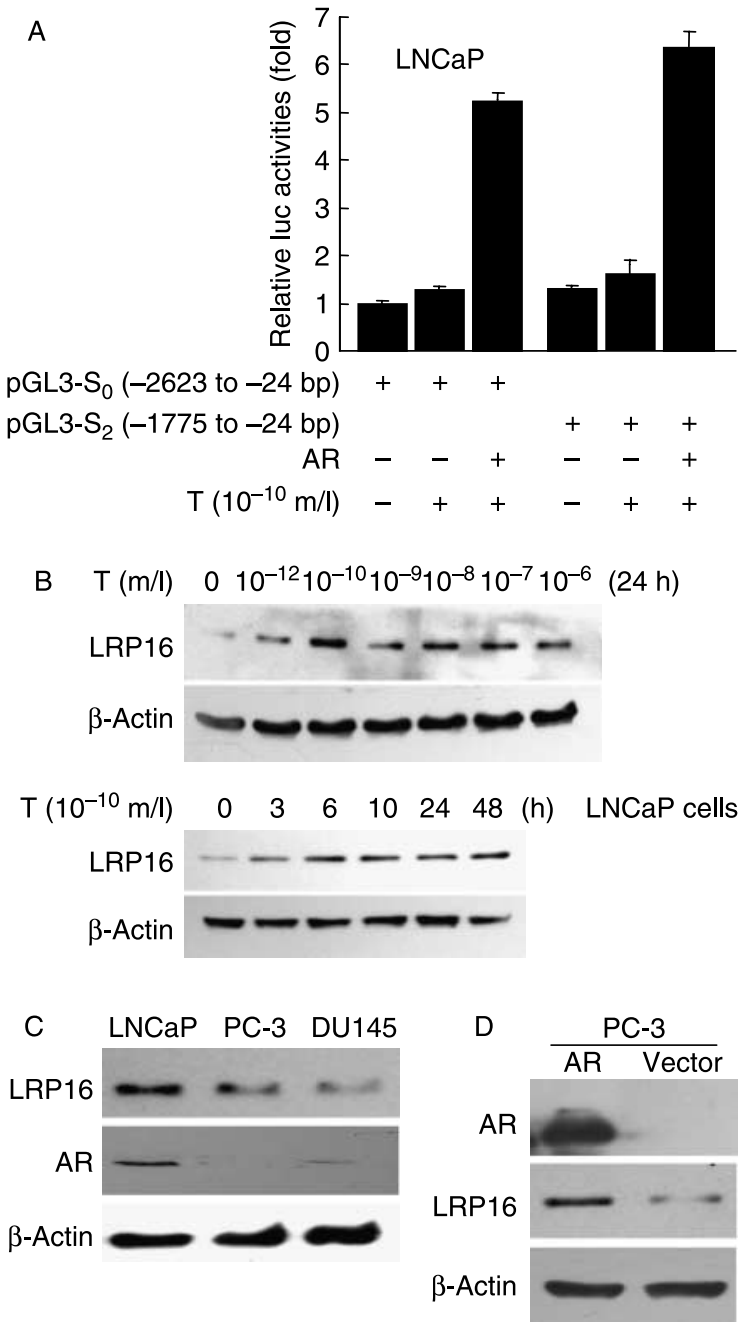

Figure 7 Androgen stimulates LRP16 promoter activity via AR and up-regulates LRP16 expression. (A) LNCaP cells were cotransfected with the indicated plasmids. Thirty-six hour after transfection, cells were treated with or without $10^{-10} \mathrm{M} / \mathrm{I}$ testosterone for an additional $12 \mathrm{~h}$ and underwent luciferase assay. The relative luciferase activity levels were normalized in all case by mock effector transfection and arbitrarily assigned a value of 1 . All experiments were performed in triplicate and were repeated at least three times; results are expressed as mean \pm S.E.M. (B) LNCaP cells were cultured in medium supplemented with steroid-stripped FBS (5\%) for 3 days, then treated with testosterone at the indicated concentration for the indicated times. Immunoblots were probed for LRP16 and $\beta$-actin. (C) Total protein from the indicated cell lines was extracted and used for monitoring the expression of AR, LRP16, and $\beta$-actin by immunoblotting assays. (D) PC-3 cells were transfected with AR or the empty vector and cultured in a medium containing non-stripped serum. Immunoblots were probed for AR, LRP16, and $\beta$-actin.

NRs in that AR-mediated transcription requires the interaction of the AR NTD with the AR LBD in a hormone-dependent manner when the AR is not bound to DNA (He et al. 2000, van Royen et al. 2007), thus possibly generating a new conformation that is important for recruitment of at least some of AR coactivators (Toumazou et al. 2008). So, another explanation for differential LRP16-binding motifs between $A R$ and $E R \alpha$ is that the interaction of LRP16 with the AR C terminus may be more suitable for the special AR configuration rather than ER $\alpha$.

ART-27 is a well-known AR coactivator that interacts with the AR $\mathrm{N}$ terminus and activates AR activity in a ligand-dependent manner (Markus et al. 2002, Taneja et al. 2004). LRP16 also interacts with ART-27, which indicates that LRP16 communicates with at least one other transcriptional regulatory cofactor of AR. SRC-1 interacts directly and ligand dependently with the AR to enhance AR-mediated transcription (Powell et al. 2004). Although SRC-1 has been shown to interact with AR AF2 , it interacts primarily with the AR N-terminus and possibly the DBD (Bevan et al. 1999, Powell et al. 2004, Heemers \& Tindall 2007). Moreover, SRC-1 functions as a scaffold protein that attracts additional coactivator proteins such as $\mathrm{p} 300$, the $\mathrm{p} 300$ homolog CREB-binding protein (CBP), and $\mathrm{p} 300 / \mathrm{CBP}-a$ ssociated factor (P/CAF; Chen et al. 1997, Spencer et al. 1997, Heemers \& Tindall 2007). Despite the lack of binding competition for the AR motif between LRP16 and ART-17 or SRC-1, we found the AR-induced transcriptional activation facilitated by both ART-27 and SRC-1 markedly diminished in LRP16-inhibited LNCaP cells (Fig. 5B), which suggests that LRP16 may play an essential role in AR transcription complex assembly after AR is exposed to ligand. Overexpression of LRP16 cannot amplify the coactivation of AR by ART-27 (Fig. 3A and B), which suggests that the endogenous LRP16 in cells is enough to support the excessive activities of other AR coactivators.

By promoter analyses and expression measurement of the LRP16 gene in androgen-sensitive LNCaP prostate cancer cells (Fig. 7), we confirmed the induction effect of LRP16 expression by androgen via $\mathrm{AR}$ mediation. In a $2.6 \mathrm{-kb}$ region of LRP16 upstream regulatory sequence (pGL3-S $\mathrm{S}_{0}$ ), which confers the androgen responsiveness as illustrated in Fig. 7A, we failed to find the canonical androgen response element (ARE) (imperfect palindrome GGTACAnnnT GTTCT) or either of the perfect halfsites. However, three sites containing imperfect AR-binding sequence (nGTACnnnnnGnnCn) were found across a 1.6-kb region of LRP16 upstream regulatory sequence. In addition, four imperfect halfsites across a 2.0-kb region of LRP16 upstream regulatory sequence were also observed. We arbitrarily proposed that one of the imperfect AREs or ARE halfsites may mainly contribute to the androgen responsiveness through AR binding to it, because it has been reported that there is a wide range of sequences that $A R$ 
can bind, typically containing the core requirement of three out of four guanines contacts at GGTACAnnnTGTTCT (Nelson et al. 1999). Certainly, we cannot exclude the possibility that LRPI6 is a secondary response gene of androgen. The molecular mechanism by which androgen upregulates LRP16 expression is being investigated in our laboratory.

Considering the essential roles of the AR activity in normal and cancerous prostate tissues, a precise understanding of the mechanisms of AR regulation is of utmost importance. The expression of most AR coactivators is out of control by AR activity. Yet, emerging evidence has demonstrated that some of the AR coactivators such as SRG3 and FHL2 are AR-regulated targets (Hong et al. 2005, Heemers et al. 2007). This positive regulatory mechanism of AR transactivation by its response targets may be important for the rapid proliferation of cells during prostate development and may be essential for AR activation during prostate cancer progression (Hong et al. 2005, Heemers et al. 2007). In this study, we established the existence of a feedforward mechanism whereby the androgen-responsive protein LRP16 activates the AR in human prostate cancer cells, which is similar to the LRP16-ER $\alpha$ feedforward regulation in estrogen-dependent breast cancer cells (Han et al. 2007). Furthermore, we also demonstrated that the inhibition of the endogenous LRP16 in androgen-sensitive prostate cancer cells markedly diminished androgen-stimulated cell growth (Fig. 6), although its overexpression did not significantly promote cell proliferation. These results indicated that the AR-LRP16 feedback pathway may play an essential role in maintaining androgen-induced AR activation. Appropriate expression of LRP16 in androgen-sensitive prostate cancer cells is critical for cell proliferation. The breakdown of this feedforward signaling might be beneficial in AR-targeting therapy of androgen-dependent prostate cancer.

\section{Declaration of interest}

The authors declare that there is no conflict of interest that could be perceived as prejudicing the impartiality of the research reported.

\section{Funding}

This study was supported by the National Natural Science Foundation of China (grants 30670809 and 30870968) and partially supported by a grant from the Ministry of Science and Technology of China (2005CB522603).

\section{Acknowledgements}

We thank Prof. Donald P McDonnell from Duke University Medical Center for providing $3 \times$ ERE-TATA-Luc plasmid and Dr Masatoshi Nomura from Kyushu University for providing MMTV-Luc and other plasmids.

\section{References}

Aguiar RCT, Takeyama K, He C, Kreinbrink K \& Shipp MA 2005 B-aggressive lymphoma family protein have unique domains that modulate transcription and exhibit poly (ADP-ribose) polymerase activity. Journal of Biological Chemistry 280 33756-33765.

Amé JC, Spenlehauer C \& de Murcia G 2004 The PARP superfamily. BioEssays 26 882-893.

Angelov D, Molla A, Perche PY, Hans F, Cote J, Khochbin S, Bouvet P \& Dimitrov S 2003 The histone variant macroH2A interferes with transcription factor binding and SWI/SNF nucleosome remodeling. Molecular Cell 11 1033-1041.

Bevan CL, Hoare S, Claessens F, Heery DM \& Parker MG 1999 The AF1 and AF2 domains of the androgen receptor interact with distinct regions of SRC-1. Molecular and Cellular Biology 19 8383-8392.

Brinkmann AO, Faber PW, van Rooij HCJ, Kuiper GGJM, Ris C, Klaassen P, van der Korput JAHM, Voorhorst MM, van Laar JH, Mulder E et al. 1989 The human androgen receptor: domain structure, genomic organization and regulation of expression. Journal of Steroid Biochemistry 34 307-310.

Chang CY \& McDonnell DP 2005 Androgen receptorcofactor interactions as targets for new drug discovery. Trends in Pharmacological Sciences 26 225-228.

Chauchereau A, Georgiakaki M, Perrin-Wolff M, Milgrom E \& Loosfelt H 2000 JAB1 interacts with both the progesterone receptor and SRC-1. Journal of Biological Chemistry 275 8540-8548.

Chen H, Lin RJ, Schiltz RL, Chakravarti D, Nash A, Nagy L, Privalsky ML, Nakatani Y \& Evans RM 1997 Nuclear receptor coactivator ACTR is a novel histone acetyltransferase and forms a multimeric activation complex with $\mathrm{P} / \mathrm{CAF}$ and $\mathrm{CBP} / \mathrm{p} 300$. Cell 90 569-580.

Corda D \& Girolamo MD 2003 Functional aspects of protein mono-ADP-ribosylation. EMBO Journal 22 1953-1958.

Culver GM, Consaul SA, Tycowski KT, Filipowicz W \& Phizicky EM 1994 tRNA splicing in yeast and wheat germ. A cyclic phosphodiesterase implicated in the metabolism of ADP-ribose 1", 2"-cyclic phosphate. Journal of Biological Chemistry 269 24928-24934.

Dehm SM \& Tindall DJ 2006 Molecular regulation of androgen action in prostate cancer. Journal of Cellular Biochemistry 99 333-344.

Dehm SM \& Tindall DJ 2007 Androgen receptor structural and functional elements: role and regulation in prostate cancer. Molecular Endocrinology 21 2855-2863.

Egloff MP, Malet H, Putics Á, Heinonen M, Dutartre H, Frangeul A, Gruez A, Campanacci V, Cambillau C, 
Ziebuhr J et al. 2006 Structural and functional basis for ADP-ribose and poly(ADP-ribose) binding by viral macro domains. Journal of Virology 80 8493-8502.

Goenka S \& Boothby M 2006 Selective potentiation of Statdependent gene expression by collaborator of Stat6 (CoaSt6), a transcriptional cofactor. PNAS 103 4210-4215.

Han WD, Yu L, Lou FD, Wang QS, Zhao Y, Shi ZJ, Jiao HY \& Zhou JJ 2001 Cloning and expression characteristics of the full length cDNA for a novel leukemia-associated gene LRP16. Academic Journal of PLA Postgraduate Medical School 17 209-214.

Han WD, Lou FD, Yu L, Han XP, Wang QS, Li N \& Zhou CX 2002 Bioinformatic analysis and subcellular distribution of LRP16 protein. Academic Journal of PLA Postgraduate Medical School 23 277-279.

Han WD, Mu YM, Lu XC, Xu ZM, Li XJ, Yu L, Song HJ, Li M, Lu JM, Zhao YL et al. 2003 Up-regulation of LRP16 mRNA by $17 \beta$-estradiol through activation of estrogen receptor $\alpha$ $\mathrm{ER} \alpha$, but not estrogen receptor $\beta \mathrm{ER} \beta$ and promotes human breast cancer MCF-7 cell proliferation: a preliminary report. Endocrine-Related Cancer 10 217-224.

Han WD, Zhao YL, Meng YG, Zang L, Wu ZQ, Li Q, Si YL, Huang K, Ba JM, Morinaga H et al. 2007 Estrogenically regulated $\mathrm{ER} \alpha$ target gene LRP16 interacts with ER $\alpha$ and enhances the receptor's transcriptional activity. Endocrine-Related Cancer 14 741-753.

Han WD, Si YL, Zhao YL, Li Q, Wu ZQ, Hao HJ \& Song HJ 2008 GC-rich promoter elements maximally confer estrogen-induced transactivation of LRP16 gene through ER $\alpha / S p 1$ interaction in MCF-7 cells. Journal of Steroid Biochemistry and Molecular Biology 109 47-56.

Hassa PO, Haenni SS, Elser M \& Hottiger MO 2006 Nuclear ADP-ribosylation reactions in mammalian cells: where are we today and where are we going? Microbiology and Molecular Biology Reviews 70 789-829.

He B, Kemppainen JA \& Wilson EM 2000 FXXLF and WXXLF sequences mediate the NH2-terminal interaction with the ligand binding domain of the androgen receptor. Journal of Biological Chemistry 275 22986-22994.

Heemers HV \& Tindall DJ 2007 Androgen receptor coregulators: a diversity of functions converging on and regulating the AR transcriptional complex. Endocrine Reviews 28 778-808.

Heemers HV, Regan KM, Dehm SM \& Tindall DJ 2007 Androgen induction of the androgen coactivator four and a half LIM domain protein-2: evidence for a role for serum response factor in prostate cancer. Cancer Research 67 10592-10599.

Hong CY, Suh JH, Kim K, Gong EY, Jeon SH, Ko M, Seong RH, Kwon HB \& Lee K 2005 Modulation of androgen receptor transactivation by the SWI3-related gene product (SRG3) in multiple ways. Molecular and Cellular Biology 25 4841-4852.

Imagama S, Abe A, Suzuki M, Hayakawa F, Katsumi A, Emi N, Kiyoi H \& Naoe T 2007 LRP16 is fused to RUNX1 in monocytic leukemia cell line with $\mathrm{t}(11 ; 21)(\mathrm{q} 13 ; \mathrm{q} 22)$. European Journal of Haematology 79 25-31.
Karras GI, Kustatscher G, Buhecha HR, Allen MD, Pugieux C, Sait F, Bycroft M \& Ladurner AG 2005 The macro domain is an ADP-ribose module. EMBO Journal 24 1911-1920.

Kraus WL \& Lis JT 2003 PARP goes transcription. Cell 113 677-683.

Kumaran D, Eswaramoorthy S, Studier FW \& Swaminathan S 2005 Structure and mechanism of ADP-ribose-1"monophosphatase (Appr-1" ${ }^{\prime \prime}$-pase), a ubiquitous cellular processing enzyme. Protein Science 14 719-726.

Kustatscher G, Hothorn M, Pugieux C, Scheffzek K \& Ladurner AG 2005 Splicing regulation NAD metabolite binding to histone macroH2A. Nature Structural and Molecular Biology 12 624-625.

Ladurner AG 2003 Inactivating chromosomes: a macro domain that minimizes transcription. Molecular Cell 12 1-4.

Lee HJ \& Chang C 2003 Recent advances in androgen receptor action. Cellular and Molecular Life Sciences 60 1613-1622.

Liao DX, Han WD, Zhao YL, Pu YD, Mu YM, Luo CH \& Li XH 2006 The expression and clinical significance of LRP16 gene in human breast cancer. Ai Zheng 25 866-870.

Markus SM, Taneja SS, Logan SK, Li WH, Ha S, Hittelman AB, Rogatsky I \& Garabedian MJ 2002 Identification and characterization of ART-27, a novel coactivator for the androgen receptor $\mathrm{N}$ terminus. Molecular and Cellular Biology 13 670-682.

McKenna NJ \& O'Malley BW 2002 Combinatorial control of gene expression by nuclear receptors and coregulators. Cell 108 465-474.

McKenna NJ, Lanz RB \& O’Malley BW 1999 Nuclear receptor coregulators: cellular and molecular biology. Endocrine Reviews 20 321-344.

Meng YG, Han WD, Zhao YL, Huang K, Si YL, Wu ZQ \& Mu YM 2007 Induction of LRP16 gene by estrogen promotes the invasive growth of Ishikawa human endometrial cancer cells through down-regulation of E-cadherin. Cell Research 17 869-880.

Nelson CC, Hendy SC, Shukin RJ, Cheng H, Bruchovsky N, Koop BF \& Rennie PS 1999 Determinants of DNA sequence specificity of the androgen, progesterone, and glucocorticoid receptors: evidence for differential steroid receptor response elements. Molecular Endocrinology 13 2090-2107.

Pehrson JR \& Fried VA 1992 MacroH2A, a core histone containing a large nonhistone region. Science 257 1398-1400.

Powell SM, Christiaens V, Voulgaraki D, Waxman J, Claessens F \& Bevan CL 2004 Mechanisms of androgen receptor signaling via steroid receptor coactivator-1 in prostate. Endocrine-Related Cancer 11 117-130.

Rosenfeld MG, Lunyak VV \& Glass CK 2006 Sensors and signals: a coactivator/corepressor/epigenetic code for integrating signal-dependent programs of transcriptional response. Genes and Development 20 1405-1428. 
van Royen ME, Cunha SM, Brink MC, Mattern KA, Nigg AL, Dubbink HJ, Verschure PJ, Trapman J \& Houtsmuller AB 2007 Compartmentalization of androgen receptor proteinprotein interactions in living cells. Journal of Cell Biology 177 63-72.

Smith S, Giriat I, Schmitt A \& de Lange T 1998 Tankyrase, a poly(ADP-ribose) polymerase at human telomeres. Science 282 1484-1487.

Spencer TE, Jenster G, Burcin MM, Allis CD, Zhou J, Mizzen CA, McKenna NJ, Onate SA, Tsai SY, Tsai MJ et al. 1997 Steroid receptor coactivator-1 is a histone acetyltransferase. Nature 389 194-198.

Taneja SS, Ha S, Swenson NK, Torra IP, Rome S, Walden PD, Huang HY, Shapiro E, Garabedian MJ \& Logan SK
2004 ART-27, an androgen receptor coactivator regulated in prostate development and cancer. Journal of Biological Chemistry 279 13944-13952.

Toumazou C, Li J \& Wong J 2008 Cofactor restriction by androgen receptor $\mathrm{N}$-terminal and $\mathrm{C}$-terminal interaction Molecular Endocrinology [in press].

White R \& Parker MG 1998 Molecular mechanisms of steroid hormone action. Endocrine-Related Cancer 5 $1-14$.

Zhao YL, Han WD, Li Q, Mu YM, Lu XC, Yu L, Song HJ, Lu JM \& Pan CY 2005 Mechanism of transcriptional regulation of LRP16 gene expression by $17-\beta$ estradiol in MCF-7 human breast cancer cells. Journal of Molecular Endocrinology 34 77-89. 